Japan, where they are almost unknown, caries has not changed at all. ${ }^{2}$ Nearly 100 clinical trials have been reported on fluoride toothpastes with mean reductions in caries ranging from zero to $50 \%$ and an overall mean of $24 \%$. The effect has been higher on teeth erupting during the trial than on teeth present when the trial began..$^{2021}$ Newly erupted teeth are incompletely mineralised and are both more susceptible to the damaging effect of sugars $^{22}$ and better able to benefit from the caries preventing action of fluoride. ${ }^{2021}$

At first sight, the recent reduction seems larger than could be accounted for by the use of fluoride toothpastes. In the clinical trials, usually lasting three years and on children 1215 years old, only eight to 12 teeth will erupt during the trial and receive the maximum benefit. In general use, however, children will be applying the toothpaste from the earliest age that they can use a toothbrush and all their permanent teeth will be in contact with fluoride immediately after eruption, thus increasing the average reduction. Furthermore, children aged under 5 are unlikely to spit out all their toothpaste, so that it remains in contact with the teeth for a longer time than occurs with older children, who usually do spit and rinse their mouths after toothbrushing. ${ }^{23}$ The effects of avoiding rinsing and delaying spitting out after using fluoride toothpastes on the concentration of fluoride in the saliva and the duration of its contact with the teeth have recently been measured. ${ }^{2+}$ The results confirm that delays in spitting out and rinsing (as occurs with young children) might increase the effectiveness of these toothpastes in reducing caries. Finally, the swallowing of residual fluoride may increase systemically the resistance to caries of developing permanent teeth.

The evidence strongly suggests, then, that fluoride toothpastes have been the main factor in the reduction of caries in Britain, where only about $10 \%$ of the population receive fluoridated water. Fluoride toothpastes are unusual in that their unrestricted use by the public seems to have made a greater impact than had been predicted from the results of well controlled clinical trials.

G NEIL JENKINS

Emeritus Professor of Oral Physiology,

University of Newcastle upon Tyne,

Newcastle upon Tyne NE2 4BW

I Glass RL, ed. The declining prevalence of dental caries. 7 Dent Res 1982:61:1304-83.

2 Rensen EC and members of a working group). (hanging patterns of oral health and implications for oral health manpower. Int Dent f 1985:35:235-51.

Anderson RJ, Bradnock $G$, Beal JF, James PMC. The reduction of dental caries prevalence in English schoolchildren. 7 Dent Res 1982;61:1311-6.

4 Fejerskov $O$. Antroft $P$, Gadegaard E. Decrease in caries experience in Danish children and young adults in the 1970s. I Dent Res 1982;61:1305-10.

5 Howard JH, Young JM. Rake A, Medina R, Alanis PJ. Reduction in DMFT and DMFS scores between 1977 and 1982 USAF military populations. F Dent Res 1984;63:182 (abstract 105.

6 Barmes DE. Indicators for oral health and their implications for developing countries. Int Dent $\gamma$ 1982;33:60-6

7 McEniery TM, Davies GN. Brisbane dental survey 1977: a comparative study of caries experience of children in Brisbane, Australia, over a 20-year period. Community Dent Oral Epidemiol 1979;7:42-50.

8 Backer-Dirks O. Posteruptive changes in dental enamel. $\mathcal{F}$ Dent Res 1966;45:503-I1

9 ven der Fehr FJ, Loe H, Theilade E. Experimental caries in man. Caries Res 1970;4:131-48.

$10 \mathrm{dc}$ Liefde B, Ritchie GR. Evaluation in dental public health in New Zealand. NZ Dent $\mathcal{7}$ 1984;80 $8-14$

11 Todd JE, Dodd T. ('hildren's dental health in the United Kingdom. London: Office of Population Censuses and Surveys, HMSO, 1985

12 Loesche $W^{\prime}$ J. Eklund SA, Burt BA. Relationship between antibiotic use and DMF scores in children. F Dem Res 1982;61:abstract 225, abstract 420

13 De Paolo DF, Soparkar PM, Tavares M, Allukian M Jr, Peterson H. A dental survey of Massachusetts schoolchildren. I Dent Res 1982;61:1356-60.

14 Jarvis PN, Lennon MA. Sugar consumption in Britain. F Dent Res 1983;62:439 (abstract 222).

15 Hackett AF, Rugg-Gunn AJ, Appleton DR, Eastoe JE, Jenkins GN. A 2-year longitudina nutritional survey of 405 Northumberland children initially aged 11.5 years. Br 7 Nut 1984;51:67-75

16 The Cocoa Chocolate and Confectionary Alliance. Annual report 1984. London: Cocoa Chocolate and Confectionary Alliance, 1985.

17 Bibby BG. Do we tell the truth about preventing caries? Joumal of Dentistry for Children 1966;33:269-79.

18 Koch G. Evidence for declining caries prevalence in Sweden. 7 Dent Res 1962;61:1340-5.

19 Murray JJ, Rugg-Gunn AJ. Fluoride toothpaste and dental caries. Fluorides in caries prevention. Bristol: Wright, 1982: 100-26.

20 Naylor MN, Emslie RD. Clinical testing of stannous fluoride and sodium monofluorophosphate dentifrices in London schoolchildren. Br Dent 7 1967;126:17-23.
21 Tucker GJ, Andlaw RJ, Burchell CK. The relationship between oral hygiene and dental caries incidence in 11-vear-old children. Br Dent 7 1976;141:75-9.

22 Miller (CD). The dental caries response to rats fed cariogenic and non-cariogenic diets for different perieds of time. 7 Nutr 1958;66:113-21.

Barnhart WE, Hiller LK, Leonard GI, Michaels SLE. Dentifrice usage and ingestion among four age groups. F Dent $R e$ s 1974:53:1307-13.

collins WJ , Weerman DA, Stephen KW Smalls MJ Salivary F concentrations following texthbrushing [Abstract]. Caries Res 1984:18:155.

\section{Hyperplastic gastropathy}

It is 94 years since Menetrier described the condition, hyperplastic gastropathy, that still carries his name. The confusion that has surrounded his eponymous disease is witnessed by a terminological pot-pourri of synonyms. ${ }^{12}$ While giant gastric mucosal folds may be due to carcinoma, lymphoma, or other less common conditions, they are the cardinal feature of primary hyperplastic gastropathy. ${ }^{13}$ This term was introduced by Ming, who classified it pathologically into mucous cell hyperplasia, glandular cell hyperplasia, or mixed mucous-glandular cell hyperplasia. ${ }^{4}$ Menetrier's disease should now be considered as a well defined condition within the spectrum of hyperplastic gastropathy corresponding to Ming's mucous cell type. It has four distinct features: large gastric mucosal folds, low or less commonly normal gastric acid secretion, increased gastric protein loss, and characteristic histological appearances. The microscopical features include foveolar hyperplasia, atrophy of the fundic glands, and pseudopyloric metaplasia. Cystic change and displacement of epithelium within the submucosa are common. Macroscopically the gastric mucosa is thrown into extravagant folds $3-4 \mathrm{~cm}$ high. The condition may affect the whole stomach but is usually localised to the body, characteristically sparing the antrum.

At the opposite end of the spectrum of hyperplastic gastropathy lies Schindler's disease, or hypersecretory hyperplastic gastropathy. ${ }^{5}$ This corresponds to Ming's glandular cell type and is characterised by large gastric mucosal folds, normal or high gastric acid secretion, normal protein metabolism, and parietal and chief cell hyperplasia with a relative or absolute reduction in mucous cells. It should be emphasised that Menetrier and Schindler's diseases represent the two extremes of the spectrum of hyperplastic gastropathy with intervening mixed forms (Ming's mixed mucous-glandular cell type). Fieber and Rickert's analysis of 50 well documented case reports of hyperplastic gastropathy shows that Menetrier's disease is the commonest type (66\%), followed by Schindler's disease $(22 \%)$ and the mixed type $(12 \%) .^{2}$

While there is some evidence that Schindler's disease may progress to Menetrier's disease and then on to atrophic gastritis, other authorities deny such progressive change. Spontaneous regression has been documented.

Hyperplastic gastropathy is over three times more common in men than women, and the average age at diagnosis is $40 .^{2}$ There is a self limiting, protein losing gastropathy of children, but its transient course, allergic background, and association with viral illness (especially cytomegalovirus) mean that it is unlikely to be related to adult Menetrier's disease. ${ }^{6}$

Theories outnumber facts about the cause of hypertrophic gastropathy. ${ }^{12}$ Two popular theories have been the trophic effect of gastrin and irritation due to duodenogastric reflux. Nevertheless, out of 14 reported cases, the serum gastrin

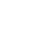
.

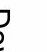


value was normal or low in eight. (The frequently raised serum gastrin concentration in the mucous cell type merely reflects hypochlorhydria or occasionally antral disease, and does not necessarily imply a causative role for gastrin.) The rarity of antral disease makes duodenogastric reflux an unlikely cause. The recent discovery of high gastric luminal concentrations of prostaglandin $\mathrm{E}_{2}$ in Menetrier's disease may be aetiologically important, especially since this agent is known to inhibit secretion of gastric acid and increase mucosal permeability.

The symptoms of hyperplastic gastropathy are common to the different variants and have been documented by Fieber and Rickert. ${ }^{2}$ The characteristic features are epigastric pain $(78 \%)$, vomiting (48\%), weight loss (41\%), peripheral oedema (40\%), and bleeding (27\%). Appropriate investigations include barium meal, gastroscopy, gastric acid studies, serum albumin estimation, protein clearance studies, and serum gastrin measurement. The diagnosis rests on histological examination of a full thickness biopsy specimen of the stomach taken at laparotomy, or possibly by using an endoscopic diathermy snare. Because of the mucosal thickness, normal endoscopic biopsy provides too shallow a sample for adequate assessment.

The relation between hyperplastic gastropathy and gastric carcinoma is controversial. ${ }^{1}$ There are at least 16 reports of carcinoma in association with histologically proved Menetrier's disease, and in four of these the gastropathy was diagnosed two to 14 years before the carcinoma appeared..$^{7-11}$ The incidence of two premalignant conditions (intestinal metaplasia and gastric adenomatous polyps) in hyperplastic gastropathy may provide the pathological link with gastric cancer, and patients who have these features should be observed closely. The incidence of malignancy in hyperplastic gastropathy is probably no greater than $5 \%$.

The inadequacy of treatment of symptomatic hyperplastic gastropathy is shown by the number of methods reported. Diet, antacids, anticholinergic drugs, prednisone, trimetaphan, $\mathrm{H}_{2}$ receptor blockade, and prostaglandins have given equivocal results. ${ }^{2}$ Surgery is reserved for diagnostic biopsy, intractable pain, protein loss, haemorrhage, pyloric obstruction, or carcinoma. Partial gastrectomy is the commonest procedure and has the advantage of reducing the mucosal area and the risk of malignancy. While incomplete excision may be followed by remission of residual disease, the risk of anastomotic leakage through diseased tissue is considerable. Total gastrectomy should be reserved for complicated proximal disease, for extensive disease, or for carcinoma. For localised disease mucosal resection is an attractive procedure, ${ }^{12}$ but more specific treatment awaits elucidation of the cause of this rare and interesting condition.

J N L SimSON

Senior Registrar,

Department of Surgery,

Guy's Hospital,

London SE1 9RT

I Cooper BT, Chadwick VS. Menetrier's disease. In: Baron JH, Moody FG, eds. Gastroenterology. 1 The foregut. London: Butterworths, 1981:141-91.

2 Fieber SS, Rickert RR. Hyperplastic gastropathy. Am f Gastroenterol 1981;76:321-9.

3 Reeder MM, Olsted WW, Cooper PH. Large gastric folds, local or widespread. $7 A M A$ 1974;320:272-4.

4 Ming SC. Tumors of the esophagus and stomach. Washington: Armed Forces Institute of Pathology, 973:115-9,153-4.

5 Lawson HH. Primary giant mucosal folds. S Afr f Surg 1975;13:33-42.

6 Burrell M, Avella J, Gryboski J, Ablow R. Transient hypertrophic gastropathy in childhood: a protein-losing gastropathy distinct from Menetrier's disease. Am J Gastroenterol 1979;72: $458-64$

Spellberg MA, Baker L. Gastritis: clinical significance with special emphasis on the tumorsimulating variety. Med Clin North Am 1953;37:41-61.

8 Games AD, Hawk WA, Owens FJ, et al. Hypertrophic gastropathy and carcinoma of the stomach. Report of a case. Gastrointest Endosc 1966;12:29-33.
9 Moeller DD, Dunn GD, Laing RR, Klotz AP. Hypertrophic gastropathy and carcinoma of the tomach. Gastrointest Endosc 1970;16:159-62.

0 Chusid EL, Hirsch RL, Colcher H. Spectrum of hyperplastic gastropathy. Arch Intern Med 1964;114:621-8.

11 Loewenthal von M, Steinitz H, Friedlander E. Gastritis hypertrophica gigantea und Magenkarzinom. Gastroenterologia (Basel) 1960;93:133-44.

12 Park WD. Giant hypertrophic gastritis. Lancet 1956;i:270,751.

\section{Handling cytotoxics}

Concern about the potential hazards of handling cytotoxic drugs is increasing, ${ }^{1-6}$ and, though few dispute the need for care with agents that may cause contact dermatitis, ${ }^{7}$ direct irritation of the skin and mucous membranes, ${ }^{8-12}$ or corneal damage, ${ }^{1314}$ controversy surrounds the mutagenic risks to hospital staff. The Ames test ${ }^{15}$ and its variant ${ }^{16}$ measure mutagenicity by assessing the effect on certain strains of bacteria, usually Salmonella typhimurium or Escherichia coli, of concentrated urine from the exposed person. Falck et al were the first to show mutagenicity in the urine of nurses handling cytotoxic drugs. ${ }^{2}$ Subsequently Staiano et al reported a lack of urine mutagenicity in eight pharmacists and concluded that this was because they handled anticancer drugs carefully. ${ }^{17} \mathrm{~A}$ further study of 10 nurses who routinely gave patients cytotoxic drugs that had been prepared by pharmacists showed no increase in mutagenicity compared with nurses who did not administer these drugs. ${ }^{18}$ Doubts about the relevance of these tests have been raised, however, by reports of increased mutagenicity in the urine of nurses who smoke and handle cytotoxic drugs but not in their nonsmoking counterparts. ${ }^{19} 20$ The results of these assays may also be confounded by dietary factors. ${ }^{21-23}$

Additional evidence on the potential effects of cytotoxic drugs comes from studies of the chromosomes of nurses handling them ${ }^{24-26}$ though the biological importance of this work has been questioned. ${ }^{27} \mathrm{~A}$ more direct method of assessing potential risk may be to measure drug absorption. Jagun et al assayed thioethers, an indicator of absorption of alkylating agents, and reported that concentrations in nurses handling cytotoxic drugs were higher after a five day work spell than after three days' holiday. ${ }^{28}$ Hirst et al found detectable amounts of cyclophosphamide in the urine of nurses who were exposed to the drug, though there was no correlation between the dose handled and the urinary concentration. ${ }^{29}$ Venitt et al failed to detect cisplatin in the urine of nurses and pharmacists routinely handling the drug, ${ }^{23}$ though again this may merely show that the precautions taken in a large cancer centre are effective. ${ }^{6}$ Studies of the air in rooms where cytotoxic drugs are prepared ${ }^{30}$ and in areas close to a horizontal laminar airflow hood ${ }^{31}$ showed detectable amounts of fluorouracil and support the concept that absorption may occur through an aerosol route. Exposure to the waste products of patients undergoing anticancer treatment may represent an additional hazard. ${ }^{32-34}$ Thus Venitt et al, while failing to detect cisplatin in nurses administering the drug, found concentrations of $7 \mathrm{mg} / \mathrm{l}$ in patients' urine. ${ }^{23}$ The results of studies of mutagenicity in nurses handling waste products are awaited.

Although the evidence suggests that hospital staff who prepare and administer cytotoxic drugs are at risk from mutagenicity, it is not conclusive and no increased incidence of cancer has been reported. Nevertheless, recommendations have been made for safe handling of cytotoxic drugs. ${ }^{35-38}$ In Britain this guidance has come from the Health and Safety Executive. ${ }^{36}$ The American Society of Hospital Pharmacists 